\title{
Discrete Element Method Simulation of Railway Ballast Compactness During Tamping Process
}

\author{
Taoyong Zhou, ${ }^{1, *}$, Bin $\mathrm{Hu}^{2}$, Junfeng $\mathrm{Sun}^{3}$ and Zhongtian Liu ${ }^{4}$ \\ ${ }^{I}$ Faculty of Mechanical and Electrical Engineering, Kunming University of Science and Technology, Kunming, Yunnan \\ 650500, China \\ ${ }^{2}$ China Railway Large Maintenance Machinery Co., Ltd. Kunming, Kunming, Yunnan 650215, China \\ ${ }^{3}$ Laboratory Center, Faculty of Mechanical and Electrical Engineering, Kunming University of Science and Technology, \\ Kunming, Yunnan 650500, China \\ ${ }^{4}$ Technology Center, China Railway Large Maintenance Machinery Co., Ltd. Kunming, Kunming, Yunnan 650215, \\ China
}

\begin{abstract}
Railway ballast tamping operation is employed in order to restore the geometry of railway track distorted by train traffics. In this paper, based on analysis of tamping principle, the discrete element analysis model of railway ballast is created using the discrete element method, numerical simulations are performed to study the change of railway ballast compactness during tamping process. This paper presents the motion trend of stone ballasts as the change trend of railway ballast compactness in qualitative analysis, and the distance between stone ballast and sleeper as the change index of railway ballast compactness in quantitative analysis. By comparing simulation data of different vibration frequencies, an optimal vibration frequency is obtained. The simulation results accord with the actual industrial tamping operation, which verifies that the discrete element method is an effective method to evaluate the change of railway ballast compactness during tamping process.
\end{abstract}

Keywords: Railway Ballast, tamping, ballast compactness, discrete element method, vibration frequency.

\section{INTRODUCTION}

Railway ballast is the railway track foundation that is composed of graded stone ballast. The increasing flow of rail transport may inevitably deform or damage the railway line. In order to ensure train safety, smoothness, and fast running, and to extend the service life of various components of the railway track, the maintenance work of the line needs to be done timely to keep the line equipment in good condition [1$3]$.

Because the ballast on newly-built railway track or the ballast just after overhaul of railway track is relatively loose, the bearing capacity and stability of railway track are very poor, so the ballast compactness is a very important index of the railway ballast. In order to improve the railway ballast compactness, the tamping operations are used. As the graded stone ballast of railway is granular media of different shapes and sizes, during tamping process, the railway ballast compactness is difficult to detect, the tamping effect is difficult to assess, and the selection of tamping parameters is usually dependent on field trials and practical experience, for lack of theoretical basis [4].

*Address correspondence to this author at the Faculty of Mechanical and Electrical Engineering, Kunming University of Science and Technology, Kunming, Yunnan 650500, China; Tel: +86-871-5186388;

Fax:+86-871-5186388; E-mail: kmzty@163.com
In recent years, the rapid development of discrete element method offers a new means of studying the response characteristics of railway ballast [5-9] during tamping process. The discrete element method was developed based on the principle of molecular dynamics by the American scholar Cundall PA in 1971, which is used to study the discrete particle materials. The basic idea of discrete element method is that arbitrary discontinuities are divided into a set of rigid elements, making each rigid element satisfy the equations of motion, use time step iteration method for solving the equations of motion of rigid elements, and then obtain the overall movement patterns of arbitrary discontinuities. After more than forty years of continuous in-depth study, the discrete element method has gained wide use in research areas involving solid particles [10-18].

It is regarded as a new attempt the use of discrete element method for creating discrete element model of railway ballast and simulating the change of railway ballast compactness during tamping process.

\section{TAMPING PRINCIPLE}

The industrial tamping device is mainly composed of frame, guide column, eccentric shaft, support arms, tamping tines, hinge pins, and hydraulic cylinders and so on, as shown in Fig. (1).

The industrial tamping device takes vibration form of crank-connecting rod and rocker as its working mode and 


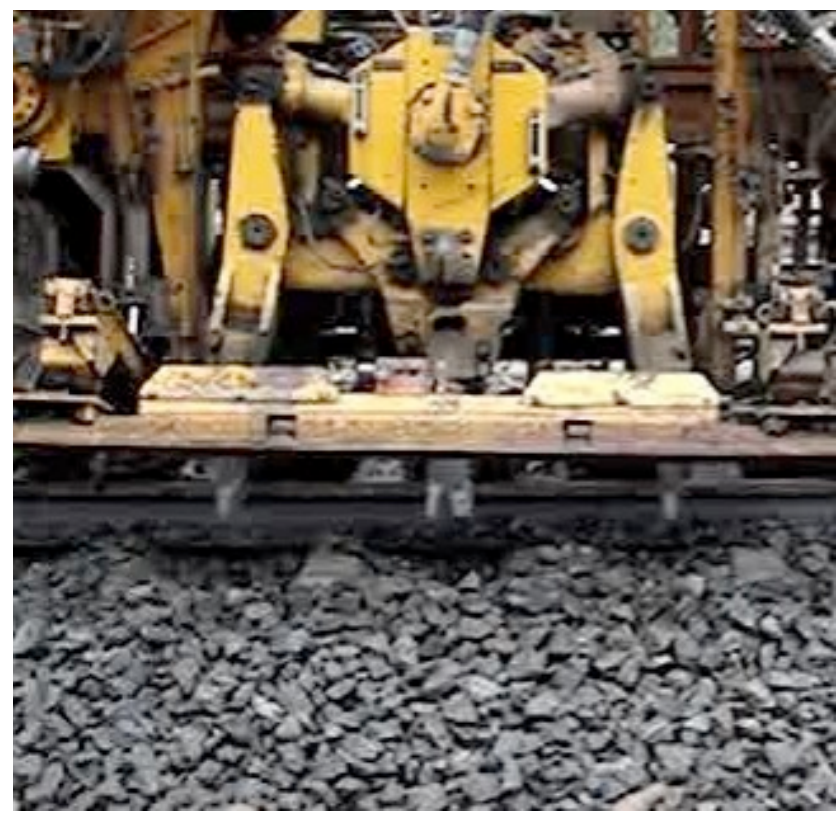

Fig. (1). Tamping device.

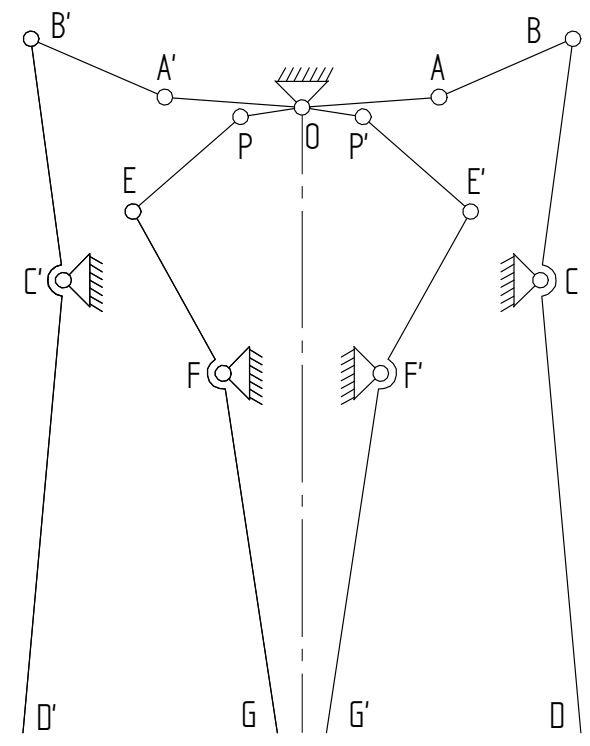

Fig. (2). Mechanism kinematic diagram of tamping device.

takes asynchronous constant pressure as its tamping principle. Tamping operation is a continuous cycle process. The cycle itself has five phases: the first phase is that the tamping tines are inserted into the ballast around the sleepers, the second phase is that the tamping tines squeeze the ballast to fill the voids under the sleeper, the third phase is keeping the squeezing, the fourth phase is loosening the squeezing, and the fifth phase is that the tamping tines are removed, as well as the tamping tines always maintain the vibration throughout the tamping operation process [19-23].

In the process of squeezing, the clamping force of tamping tine and the ballast resistance constitute a pair of action and reaction, that is to say, the clamping force is equal to the ballast resistance. Due to the hydraulic system pressure which drives hydraulic cylinder is the same, when the ballast is loose, the ballast resistance is small, the speed of movement of the tamping tine is faster, so the movement of differ- ent tamping tines is not synchronized during the process of squeezing, and this is called asynchronous principle.

When the railway ballast is constantly squeezed, the railway ballast becomes more and more dense, and the ballast resistance keeps on increasing. When the ballast resistance and the driving force of hydraulic cylinder achieve balance, the squeezing motion is stopped, the railway ballast achieves the same compactness, and this is called the constant pressure principle.

To maintain the clamping force for a period of time, the hydraulic cylinder will reverse movement, the tamping tine will be opened, the tamping device will be lifted, and the tamping tine will be removed from the railway ballast, then the tamping operation cycle is over. The mechanism kinematic diagram of tamping device is shown in Fig. (2). 


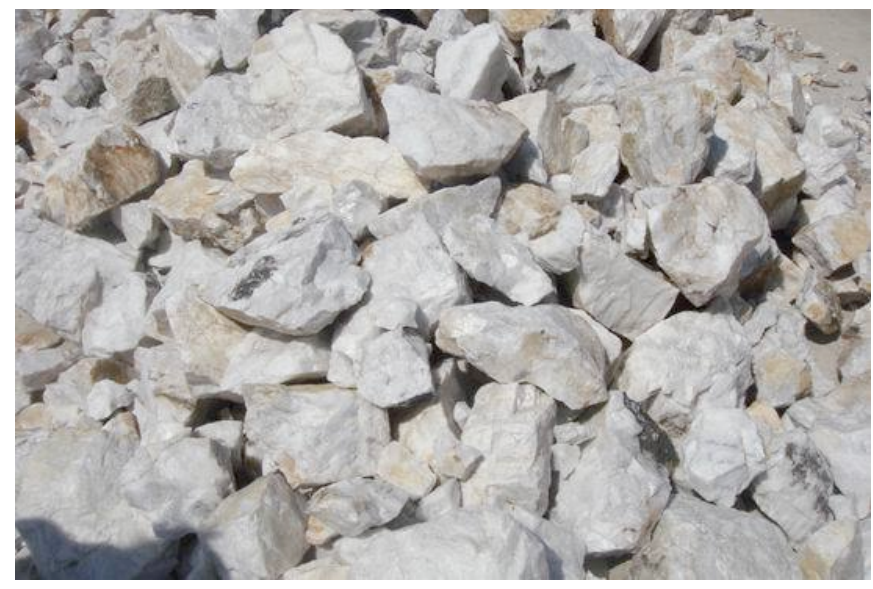

Fig. (3). Actual shape of stone ballast.

During the tamping process, the vibration force is transferred to the stone ballast through tamping tines, then the stone ballast generates vibration and moves to stable direction, which increases the railway ballast compactness; on reuse of the clamping force which is provided by tamping tines, the stone ballast between sleepers is squeezed to the voids under sleeper, which further increases the railway ballast compactness under sleeper, so as to improve the stability of the track.

\section{DISCRETE ELEMENT ANALYSIS MODEL}

This paper tries to create the analysis model of railway ballast using the discrete element method in the discrete element analysis software EDEM, which was provided by DEM Solutions Ltd as international common discrete element analysis software. In order to improve the calculation speed, the analysis models need to be simplified. Discrete element analysis model of railway ballast during tamping process is mainly composed of particle model of stone ballast, contact model of stone ballast, geometry model of sleepers and tamping tines, model domain, and particle factories of railway ballast and so on.

\subsection{Particle Model of Stone Ballast}

At present the basic particle shape model is sphere in the three-dimensional discrete element analysis software, however, the shape of stone ballast is irregular, the size of stone ballast is also inconsistent, and as shown in Fig. (3), which brings some difficulties to simulation analysis [24-35].

In the three-dimensional discrete element analysis software EDEM, overlapping spherical surfaces of different sizes are used to form complex clumps in order to simulate particles of irregular shape, this paper creates two typical particle models to simulate the real stone ballast by mean of overlapping spherical surfaces of different sizes, as shown in Fig. (4).

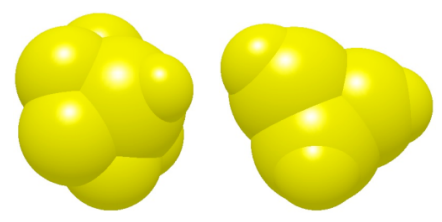

Fig. (4). Particle model of stone ballast.

\subsection{Contact Model of Stone Ballast}

The interaction forces acting on the particles of stone ballast contain pressure and friction, the normal force generally uses the Hertz contact model to calculate, the tangential force generally uses the Mindlin-Deresiewicz contact model to calculate. The normal contact model is shown in Fig. (5a), the tangential contact model is shown in Fig. (5b).

According to the Hertz-Mindlin contact theory, the mechanics model of particle uses vibration equations of motion to simulate. In the process of particle contact, the normal vibration equation of motion is given by Eq. (1); the tangential vibration of motion contains tangential sliding and rolling of particle, which is given by Eq. (2) and Eq. (3).

$$
\begin{aligned}
& m_{1,2} d^{2} u_{n} / d t^{2}+c_{n} d u_{n} / d t+K_{n} u_{n}=F_{n} \\
& m_{1,2} d^{2} u_{s} / d t^{2}+c_{s} d u_{s} / d t+K_{s} u_{s}=F_{s} \\
& I_{1,2} d^{2} \theta / d t^{2}+\left(c_{s} d u_{s} / d t+K_{s} u_{s}\right) r=M
\end{aligned}
$$

Where $m_{1,2}$ is the equivalent mass of particle 1,$2 ; I_{1,2}$ is the equivalent moment of inertia of particle 1,$2 ; r$ is the radius of gyration; $F_{n}$ is the normal component of external force acting on particles; $F_{s}$ is the tangential component of external force acting on particles; $M$ is the external torque acting on particles.

For the tangential sliding and rolling of particle are influenced by the friction between the particles, in addition to the Poisson's ratio, shear modulus and density of the materials properties of particles, the friction coefficient of particles should be defined in EDEM.

\subsection{Geometry Model of Sleepers and Tamping Tines}

Since the industrial tamping device and railway track are very complex, and some parts have no effect on the simulation results, in order to improve the calculation speed, the geometry model needs to be simplified. The sleeper and tamping tines are selected as main geometry analysis model in this paper, for they contact with stone ballast in the simulation and have key effect on the simulation results. 


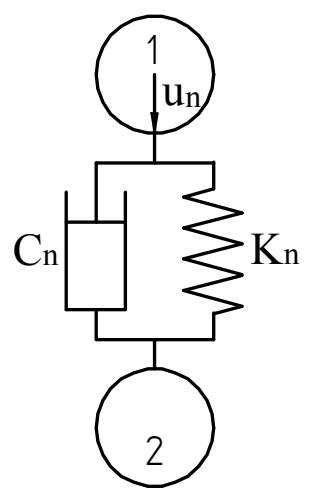

(a)

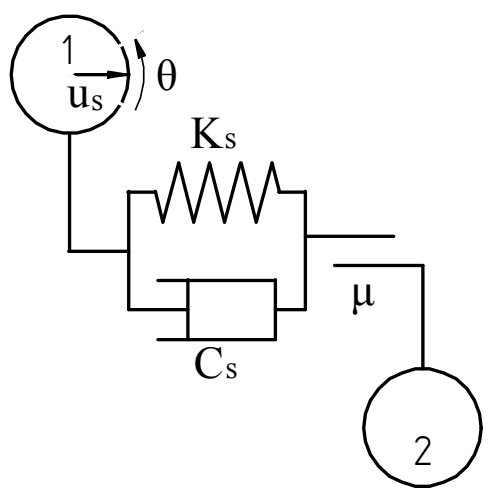

(b)

Fig. (5). Contact model of stone ballast.

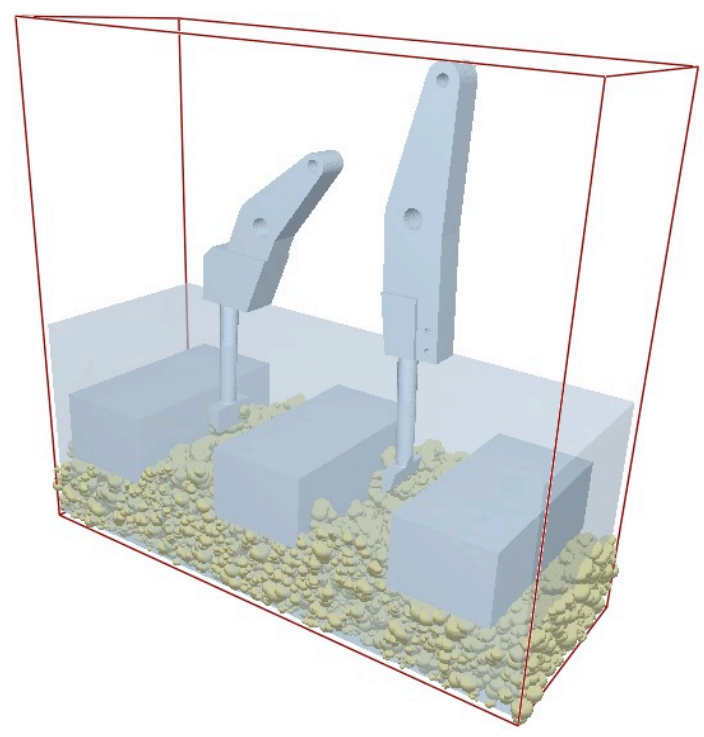

Fig. (6). Analysis model of tamping operations.

Geometry model can be defined in EDEM or imported from a CAD package. In this paper, since the structure of sleeper and tamping tine are more complex, the geometry model of sleepers and tamping tines are created in Solid Edge, and then imported into EDEM.

After the geometry model of sleepers and tamping tines are created and located, some geometry attributes need to be defined in EDEM. In addition to the Poisson's ratio, shear modulus and density of the materials properties of sleepers and tamping tines, the dynamic properties of tamping tines should be defined in EDEM. In this paper, the dynamic properties of tamping tine are defined through the reference of the actual industrial tamping operation process which was recommended by the China Railway Large Maintenance Machinery Co., Ltd. Kunming. There are five phases in a tamping operation cycle: the first phase is that the tamping tines are inserted into the ballast around the sleepers, the second phase is that the tamping tines squeeze the ballast to fill the voids under the sleeper, the third phase is keeping the squeezing, the fourth phase is loosening the squeezing, and the fifth phase is that the tamping tines are removed, as well as the tamping tines always maintain the vibration throughout the tamping operation process. The simulation is continuous tamping operation twice in a tamping process in this paper.

\subsection{Model Domain}

The model domain is the area in which simulation takes place. The EDEM Simulator stops tracking any particle that moves out of the model domain during the course of the simulation. Domain size has an effect on simulation time: the larger the domain, the longer the simulation will take to run.

In this paper, the option of auto update from geometry is selected in EDEM, the model domain is set automatically according to the geometry size, and the simulation area is created as small as possible.

\subsection{Particle Factories of Railway Ballast}

Particle factories are used to define where, when and how particles appear in a simulation. Any virtual surface or volume can be turned into a particle factory. For simulating the railway ballast bed, a virtual box is created to be turned into a particle factory, and some associated parameters are defined in this paper.

The discrete element analysis model of railway ballast during tamping process has been created by creating the particle and contact model of stone ballast, the geometry model of sleepers and tamping tines, and particle factories of railway ballast, and so on, as shown in Fig. (6). 


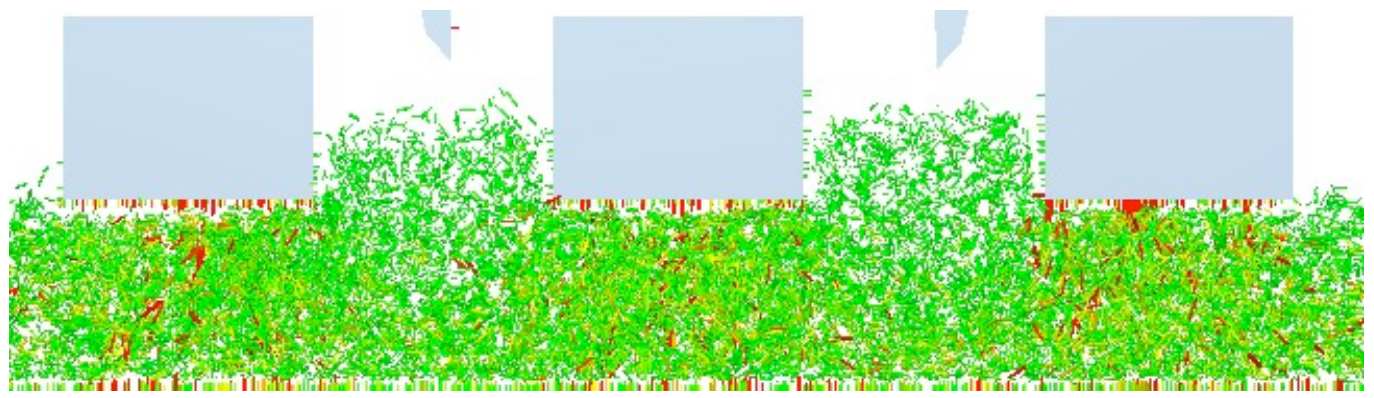

Fig. (7). Motion trend of stone ballasts during tamping process.

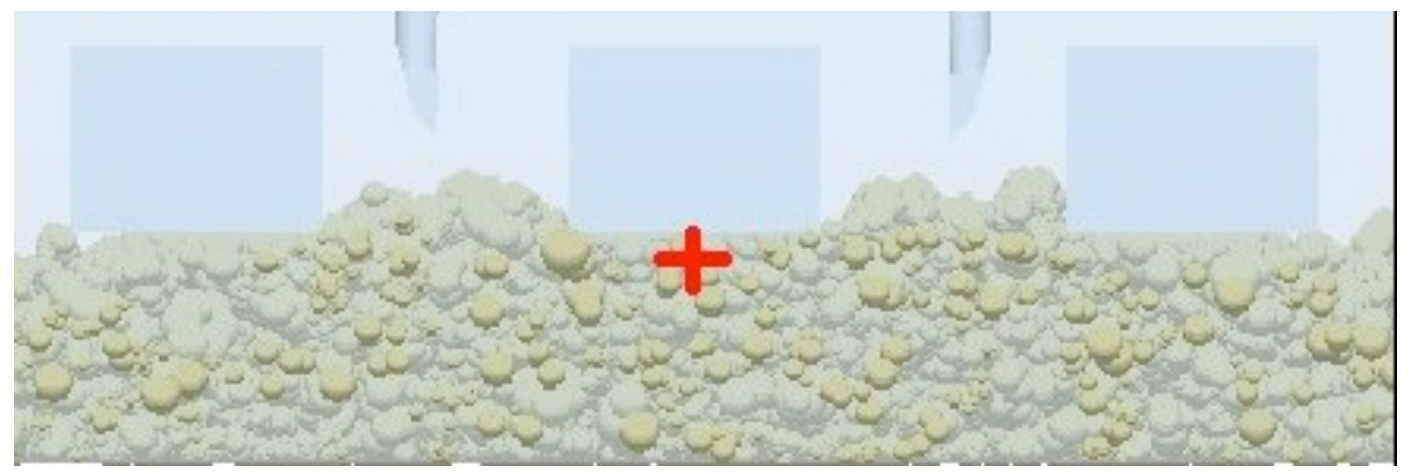

Fig. (8). Sketch of the measuring point under sleeper.

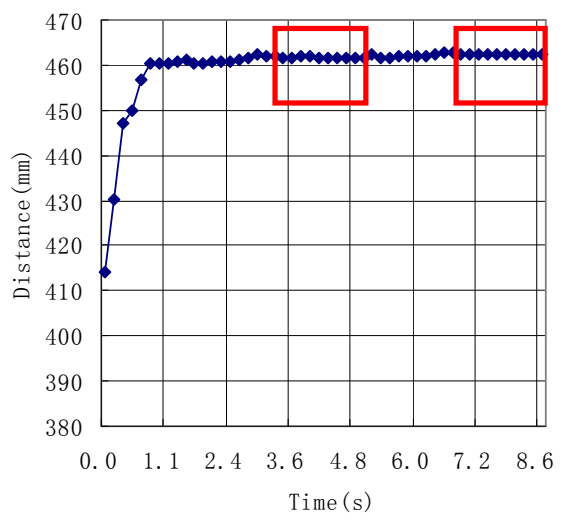

Fig. (9). Distances between stone ballast and the measuring point during tamping process.

\section{SIMULATION ANALYSIS}

In this paper, the simulation analysis is conducted to study the railway ballast compactness during tamping process. In order to qualitatively study the change of railway ballast compactness, we extract the motion trend of the stone ballasts during tamping process which reflects the change of railway ballast compactness. In order to quantitatively study the change of railway ballast compactness, we extract the distances between stone ballast and the sleeper from the simulation which reflects the change of railway ballast compactness.

\subsection{Motion Trend of Stone Ballasts}

In the process of tamping operations, stone ballast under the action of vibration force and clamping force will produce motion. In order to qualitatively study the change of railway ballast compactness during tamping process, in the process of simulation, we extract the motion trend of the stone ballasts as shown in Fig. (7). It clearly shows that the stone bal- lasts between sleepers are moved to fill the voids under sleeper during the process of tamping operation, which increases the railway ballast compactness under sleeper.

\subsection{Distance Between Stone Ballast and Sleeper}

The distance can be measured from any particle to a specific point in EDEM. The specific point can be defined according to actual need. In order to quantitatively study the railway ballast compactness under sleeper, the point marked with "+" is defined as the measuring point under sleeper in this paper, as shown in Fig. (8).

In the process of tamping operations, the distances between various stone ballasts and the measuring point under sleeper are not equal. This paper extracts the average of distances between stone ballast and the measuring point under sleeper from the simulation, as shown in Fig. (9), which means that during the process of continuous tamping operation, the average distances between stone ballast and the measuring point under sleeper change with time. The box 


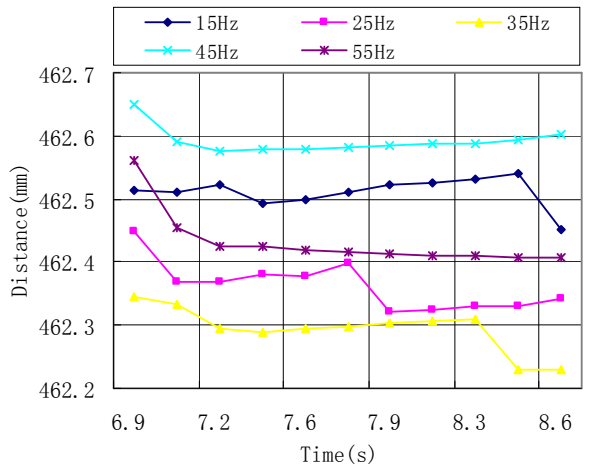

Fig. (10). Comparison of the distances after tamping operation at different vibration frequencies

part in Fig. (9) shows the average distances between stone ballast and the measuring point under sleeper change with time during the phase when the tamping tines are removed from the railway ballast.

Since vibration frequency of tamping tine has important effect on the railway ballast compactness during tamping process, we select the vibration frequency of tamping tine as main tamping parameter to study in this paper. In order to quantitatively study the change of railway ballast compactness during tamping process under different vibration frequency, the simulation analysis is conducted by changing the vibration frequency of tamping tines in the case of other tamping parameters unchanged.

The vibration frequency is determined by setting the oscillating frequency of geometry in EDEM. The oscillating frequency of tamping tines is set at $15 \mathrm{~Hz}, 25 \mathrm{~Hz}, 35 \mathrm{~Hz}, 45 \mathrm{~Hz}$ and $55 \mathrm{~Hz}$ in this paper. Then the simulations are carried out with the different vibration frequencies to compare the railway ballast compactness during tamping process.

This paper compares the change of the average distances between stone ballast and the measuring point under sleeper after two successive tamping operations at different vibration frequency, which compares the curve in the second box of Fig. (9) at different vibration frequency, as shown in Fig. (10). It can be seen from Fig. (10), when vibration frequency is $35 \mathrm{~Hz}$, the average distances between stone ballast and the measuring point under sleeper are relatively small.

\section{CONCLUSIONS}

The discrete element analysis method has been used to simulate the change of railway ballast compactness during tamping process, according to the discrete characteristics of railway ballast.

According to the previous qualitative simulation analysis, in the process of tamping operation, the stone ballasts between sleepers are moved to fill the voids under sleeper which increases the railway ballast compactness under sleeper. The simulation result accords with the actual industrial tamping operation.

According to the previous quantitative simulation analysis, when the vibration frequency of tamping tines is $35 \mathrm{~Hz}$, the average distances between stone ballast and the measuring point under sleeper are relatively small, which means that the railway ballast compactness under sleeper is relatively dense, the effect of tamping operation is better. That is to say, in the process of numerical simulation, $35 \mathrm{~Hz}$ is the optimal vibration frequency of tamping tines during tamping process. The simulation optimal vibration frequency is consistent with the recommended vibration frequency of China Railway Large Maintenance Machinery Co., Ltd. Kunming.

The simulation results verify that the discrete element method is an effective method to evaluate the change of railway ballast compactness during tamping process. The present study can be helpful for the analysis of the internal mechanism of ballast compaction during tamping process. Future work will be focused on further in-depth study of the mechanical properties of railway ballast during tamping process under different tamping parameters.

\section{CONFLICTS OF INTEREST:}

The authors confirm that this article content has no conflicts of interest.

\section{ACKNOWLEDGEMENTS}

This work was financially supported by the National Natural Science Foundation of China (11002062), and the Provincial Application Foundation Research Project of Yunnan, China (2011FB028).

\section{REFERENCES}

[1] V. Cecilia, M.R. Isabel, and C. Rui, "Integer Programming to Optimize Tamping in Railway Tracks as Preventive Maintenance", $J$. Transp. Eng., vol. 138, no. 1, pp. 123-131, 2011.

[2] B. Indraratna, P.K. Thakur, and J.S. Vinod, "Experimental and Numerical Study of Railway Ballast Behavior under Cyclic Loading”, Int. J. Geomech., vol. 10, no. 4, pp. 136-144, 2010.

[3] W.M. Zhai, K.Y. Wang, and J.H. Lin, "Modelling and experiment of railway ballast vibrations", J. Sound Vib., vol. 270, pp. 673-683, 2004.

[4] Z. Shugu, S. Xiaolou, and L. Chengao, "The Basic Physical and Mechanical Properties of Ballast Layer", China Railway Science, vol. 5, no. 1, pp. 60-71, 1984.

[5] G. Saussine, E. Azema, R. Peales, and F. Radjai, "Compaction of Railway Ballast During Tamping Process: a Parametric Study", Powders and Grains, vol. 1145, pp. 469-472, 2009.

[6] Z. Taoyong, H. Bin, W. Xuejun, and Y. Bo, "Discrete Element Method Analysis of Mechanical Properties of Railway Ballast during Tamping Process under Different Vibration Frequency", $A p$ plied Mechanics and Materials, vol. 190-191, pp. 369-372, 2012.

[7] Z. Taoyong, H. Bin, W. Xuejun, and Y. Bo, "Discrete Element Method Analysis of Mechanical Properties of Railway Ballast dur- 
ing Tamping Process under Different Amplitude", Applied Mechanics and Materials, vol. 233, pp. 224-227, 2012.

[8] P.A. Cundall, "The Measurement and Analysis of Acceleration on Rock Slopes", Ph.D. thesis, University of London, United Kingdom, 1971.

[9] P.A. Cundall, and O.D.L. Strack, "Discrete Numerical Model for Granular Assemblies", Geotech., vol. 29, no. 1, pp. 47-65, 1979.

[10] H. Guoming, Analysis and simulation of granular system by discrete element method using EDEM, Wuhan: Wuhan University of Technology Press, 2010.

[11] J. Weili, and F. Junjie, "Using of distinct element method to analyze granular ballast bed", J. China Railway Soc., vol. 23, no. 4, pp. 98-101, 2001.

[12] X. Hong, G. Liang, and H. Bowen, "Analysis of Ballast Dynamic Behavior with 3D Discrete Element Method", J. Railway Eng. Soc., no. 9, pp.14-17, 2009.

[13] S. Lobo-Guerrero, and L. E. Vallejo, "Discrete element method analysis of railtrack ballast degradation during cyclic loading", Granular Matter, vol. 8, pp. 195-204, 2006.

[14] M. Lu, and G.R. McDowell, "Discrete element modelling of railway ballast under monotonic and cyclic triaxial loading", Geotech., vol. 60 , no. 6 , pp. $459-467,2010$.

[15] G. Augustin, G. Gudehus, and G. Huber, "Numerical model and laboratory tests on settlement of ballast track", System dynamic and long-term behaviour of railway vehicles, track and subgrade, vol. 6, pp.317-366, 2003.

[16] Y.-M. Kim, "A Granular motion simulation by discrete element method", J. Mech. Sci. Technol., vol. 22, pp. 812-818, 2008.

[17] H. Huang, and E. Tutumluer, "Discrete Element Modeling for fouled railroad ballast", Construction and Building Materials, vol. 25, no. 8, pp. 3306-3312, 2011.

[18] Y. Yan, and S. Ji, "Discrete element modeling of direct shear tests for a granular material”, Int. J. Num. Anal. Meth. Geomech., vol. 34, no. 9, pp. 978-990, 2010.

[19] S.F. Brown, B.V. Brodrick, N.H. Thom, and G.R. McDowell, "The Nottingham railway test facility, UK", Transport, vol. 160, no. 2, pp. 59-65, 2007.

[20] G.R. McDowell, W.L. Lim, A.C. Collop, R. Armitage, and N.H. Thom, "Comparison of ballast index tests for railway trackbeds", Geotech. Eng., vol. 157, no. 3, pp.151-161, 2004.

[21] G.R. McDowell, W.L. Lim, A.C. Collop, R. Armitage, and N.H. Thom, "Laboratory simulation of train loading and tamping on ballast", Proceedings of the Institution of Civil Engineers: Transport, vol. 158, no. 2, pp. 89-95, 2005.

[22] W. Koc, A. Wilk, P. Chrostowski, and S. Grulkowski, "Tests on lateral resistance in railway tracks during the operation of a tamp- ing machine", Proceedings of the Institution of Mechanical Engineers, Part F: Journal of Rail and Rapid Transit, vol. 225, No. F3, pp. 325-340, 2011.

[23] W.L. Lim, "Mechanics of Railway Ballast Behaviour", Ph.D. thesis, University of Nottingham, United Kingdom, 2004.

[24] H. Kruse, and K. Popp, "Model-based investigation of the dynamic behaviour of railway ballast", System dynamic and long-term behaviour of railway vehicles, track and subgrade, vol. 6, pp. 275294, 2003.

[25] J.-F. Ferellec, and G. R. McDowell, "A method to model realistic particle shape and inertia in DEM", Granular Matter, no. 12, pp. 459-467, 2010

[26] M. Lu, and G.R. McDowell, "The importance of modelling ballast particle shape in the discrete element method", Granular Matter, no. 9, pp. 69-80, 2007.

[27] G. Saussine, "Modelling ballast behaviour under dynamic loading. Part 1: A 2D polygonal discrete element method approach", Computer methods in applied mechanics and engineering, vol. 195, no. 19-22, pp. 2841-2859, 2006.

[28] D.O. Potyondy, and P.A. Cundall, "A bonded-particle model for rock”, Rock Mechanics \& Mining Sciences, vol. 41, pp.1329-1364, 2004.

[29] J. Guoqing, F. Kun, G. Liang, and W. Jun, "DEM Simulation of Ballast Degradation and Breakage under Cyclic Loading", Journal of Southwest Jiaotong University, vol. 47, no. 2, pp. 187-191, 2012.

[30] C. Ergenzinger, R. Seifried, and P. Eberhard, "A Discrete Element Approach to Model Breakable Railway Ballast”, J. Fuel Cell Sci. Technol., vol. 7, no. 4, pp. 041010:1-8, 2011.

[31] Y. Ying, D. Shaocheng, S. Yong, and J. Shunying, "Discrete element analysis of elastic modulus of railway ballasts in wind with different sand contents", Chinese J. Comput. Mech., vol. 29, no. 3, pp. 439-445, 2012.

[32] M. Stahl, and H. Konietzky, "Discrete element simulation of ballast and gravel under special consideration of grain-shape, grain-size and relative density", Granular Matter, vol. 13, no. 4, pp. 417-428, 2011.

[33] W.L. Lim, and G.R. McDowell, "Discrete element modeling of railway ballast", Granular Matter, vol. 7, pp. 19-29, 2005.

[34] H. Huang, and S. Chrismer, "Discrete element modeling of ballast settlement under trains moving at critical Speeds", Construction and Building Materials, vol. 38, pp. 994-1000, 2013.

[35] W.F. Anderson, and P. Fair, "Behavior of Railroad Ballast under Monotonic and Cyclic Loading", J. Geotech. Geoenviron. Eng., vol. 134, no. 3, pp. 316-327, 2008.

Received: July 02, 2013

Revised: July 07, 2013

Accepted: July 25, 2013

(C) Zhou et al.; Licensee Bentham Open .

This is an open access article licensed under the terms of the Creative Commons Attribution Non-Commercial License (http://creativecommons.org/licenses/by-nc/3.0/) which permits unrestricted, non-commercial use, distribution and reproduction in any medium, provided the work is properly cited. 